\title{
Os desafios da inserção formal de produtos da agricultura familiar no mercado ${ }^{1}$
}

\author{
DIMAS DE OLIVEIRA ESTEVAM \\ Universidade do Extremo Sul Catarinense \\ GIOVANA ILKA JACINTO SALVARO \\ Universidade do Extremo Sul Catarinense \\ VANDA JANDIRA DALA DOS SANTOS \\ Universidade do Extremo Sul Catarinense
}

\section{Resumo}

O mercado agroalimentar brasileiro é majoritariamente dominado pelas grandes empresas nacionais e multinacionais que criam barreiras à entrada de produtos advindos da agricultura familiar. Embora, no Brasil, tenha-se um conjunto de políticas públicas de apoio à comercialização da agricultura familiar, como o Programa Nacional de Alimentação Escolar (PNAE) e o Programa de Aquisição de Alimentos (PAA), que reforçam a produção de alimentos, ao mesmo tempo existe um quadro regulatório restritivo, que exclui parte dos agricultores familiares do mercado. Mesmo assim, o País possui um vasto e diversificado mercado agroalimentar, que se mantém com base em um saber-fazer repassado de geração a geração, valorizado pelos consumidores que buscam produtos diferenciados e saudáveis. 0 reconhecimento de produtos artesanais não é garantia de facilidades de acesso ao mercado; ao contrário, a valorização aumenta as dificuldades devido às pressões no cumprimento da legislação. Nesse sentido, o presente artigo tem como objetivo analisar os desafios enfrentados pelos agricultores familiares para se inserirem formalmente no mercado sul catarinense. $O$ procedimento metodológico adotado nesta pesquisa é a descrição, com base em fontes documentais e entrevistas realizadas com dirigentes de oito cooperativas de agricultores familiares da região sul catarinense. Os resultados obtidos evidenciam que os agricultores têm acessado o mercado formalmente, por intermédio de suas cooperativas, além de produzirem para o autoconsumo e comercializarem seus produtos em mercados tradicionais, institucionais e, parte, informalmente, em domicílios e feiras.

Palavras-chave: Produtos artesanais. Mercado formal. Agricultura familiar.

\footnotetext{
O presente artigo é resultado de um Plano de Trabalho (Pibic) aprovado pelo Edital Unesc no 09/2016 e pelo Edital $\mathrm{MCTI} / \mathrm{CNPQ} / \mathrm{MEC} / \mathrm{CAPE}$

S no 22/2014. Uma versão preliminar desse artigo foi apresentado no XXXI Congreso Asociación Latinoamericana de Sociología (ALAS), realizado no mês de dezembro de 2017 em Montevidéu - Uruguai.
} 
The challenges of the formal insertion of family agriculture products into the market

\begin{abstract}
The Brazilian agri-food market is dominated by large national and multinational companies that create barriers to entry of products from family agriculture. Although the National School Feeding Program (PNAE) and the Food Acquisition Program (PAA), which reinforce food production at the same time, Brazil, as well as the set of public policies to support the commercialization of family agriculture. At the same time there is a restrictive regulatory framework which excludes part of the family farmers from the market. Even so, the country has a vast and diversified agri-food market, which is maintained based on a know-how passed on from generation to value, valued by consumers seeking differentiated and healthy products. The recognition of artisanal products is not a guarantee of easy access to the market; on the contrary, appreciation increases as difficulties due to enforcement pressures. In this sense, the present article aims to analyze the challenges faced by family farmers to formally enter the market in southern Santa Catarina. The methodological procedure adopted in the research is a description, based on documentary sources and interviews conducted with leaders of eight family farmer cooperatives in the southern region of Santa Catarina. The results show that the farmers are accessed through their cooperatives, as well as producing for their own consumption and marketing their products in traditional and institutional markets and, informally, in households and fairs.
\end{abstract}

Keywords: Handmade products. Formal market. Family farming.

\title{
Los retos de la inserción formal de los productos de la agricultura familiar en el mercado
}

\section{Resumen}

El mercado agroalimentario brasileño es mayoritariamente dominado por las grandes empresas nacionales y multinacionales que crean barreras a la entrada de productos provenientes de la agricultura familiar. Aunque en Brasil se tiene un conjunto de políticas públicas de apoyo a la comercialización de la agricultura familiar, como el Programa Nacional de Alimentación Escolar (PNAE) y el Programa de Adquisición de Alimentos (PAA), que refuerzan la producción de alimentos, al mismo tiempo existe un marco regulatorio restrictivo, que excluye parte de los agricultores familiares del mercado. Sin embargo, el país posee un vasto y diversificado mercado agroalimentario, que se mantiene con base en un saber hacer repasado de generación a generación, valorado por los consumidores que buscan productos diferenciados y saludables. El reconocimiento de productos artesanales no es garantía de facilidades de acceso al mercado; por el contrario, la valorización aumenta las dificultades debido a las presiones en el cumplimiento de la legislación. En este sentido, el presente artículo tiene como objetivo analizar los desafíos enfrentados por los agricultores familiares para insertarse formalmente en el mercado sur catarinense. El procedimiento metodológico adoptado en esta investigación es la descripción, con base en fuentes documentales y entrevistas realizadas con dirigentes de ocho cooperativas de agricultores familiares de la región sur catarinense. Los resultados obtenidos evidencian que los agricultores han accedido al mercado formalmente, a través de sus cooperativas, además de producir para el autoconsumo y comercializar sus productos en mercados tradicionales, institucionales y, una parte, informalmente, en domicilios y ferias.

Palabras clave: Productos artesanales. Mercado formal. Agricultura familiar. 


\section{Introdução}

Este artigo busca analisar os desafios da inserção formal de produtos da agricultura familiar no mercado. Resulta de pesquisas realizadas na região sul do Estado de Santa Catarina durante o ano de 2016. Nessa região, os agricultores familiares produzem e comercializam sua produção, transitando entre o mercado formal e o informal (ESTEVAM; SALVARO, 2016).

O mercado agroalimentar brasileiro é majoritariamente dominado pelas grandes empresas nacionais e multinacionais. Esse predomínio reproduz características históricas do País de produzir commodities voltadas para o mercado externo. Atualmente, o agronegócio é responsável por equilibrar o balanço de pagamentos, tornando o País reconhecido pelo dinamismo de sua agricultura em larga escala. No entanto, existem milhares de agricultores familiares distribuídos por todo o território nacional, que produzem e comercializam grandes variedades de alimentos para o consumo interno.

Nas últimas décadas, testemunha-se a valorização da agricultura familiar por meio de um conjunto de políticas públicas essencialmente voltadas para o acesso ao mercado da pequena produção familiar - dentre as quais se destaca o Programa Nacional de Alimentação Escolar-PNAE e o Programa de Aquisição de Alimentos-PAA. Essas políticas reforçam a produção de alimentos e a comercialização nesses Programas, porém, simultaneamente, tem-se um quadro regulatório voltado à grande indústria agroalimentar, restritivo para a pequena produção familiar e que exclui parte desses agricultores, empurrando-os, consequentemente, para fora do mercado (DORIGON; RENK, 2014).

Além dos programas institucionais, o mercado para produtos da agricultura familiar está aquecido devido às novas demandas de consumidores em face às mudanças nos hábitos alimentares, que têm levado em consideração seus atributos e valores culturais. Essas características são expressas nas relações de proximidade entre produtores e consumidores, com base em aspectos históricos, tradição, modo de vida, preocupação com a segurança alimentar e, de modo geral, no saber-fazer cultural do seu processo de produção.

Dessa forma, tem-se, de um lado, o debate sobre a qualidade dos alimentos, institucionalizada no mercado formal pelos padrões de qualidade, regulamentos e exigências técnicas, e, de outro, a dimensão da qualidade com base nos valores culturais e simbólicos dos alimentos, os quais vêm sendo incorporados no mercado "informal"2 de produtos alimentícios.
2 Neste artigo, compreende-se por "informal" a atividade que, não sendo ilegal, processa-se sem cumprir alguma regulação do Estado, sendo a mais frequente o não cumprimento da legislação tributária em alguns de seus aspectos. 
Além disso, a construção de novos mercados e/ou a expansão dos existentes não acontece sem tensões e negociações entre diferentes atores sociais acerca dos limites da mercantilização admitidos socialmente. Atualmente, para Dorigon e Renk (2014), novas formas de inserção no mercado estão sendo constituídas, tendo como característica principal ampliar os limites morais dos mercados institucionalizados. Esse movimento suscita reações diversas, exigindo novas negociações, que ultrapassam as características qualitativas dos produtos. Essa dimensão expansionista dos mercados tem levado a mobilizações coletivas, tanto favoráveis como contrárias a esses mercados, visando a alterações nos marcos regulatórios vigentes (DORIGON, 2010).

A existência de mercados informais pode representar algum risco à saúde, por não seguir todos os ritos e processos formais. No entanto, Wilkinson e Mior (1999) ressaltam que os agricultores familiares não agem deliberadamente ao adotarem formas produtivas baseadas em suas tradições. Além disso, há deficiências quanto ao acesso à informação e inadequações nos marcos regulatórios, muitas vezes incompatíveis com a realidade da produção artesanal. Esses fatores remetem a críticas ao sistema agroalimentar dominante e abrem novas perspectivas para a produção de alimentos tradicionais da agricultura familiar.

Partindo dessa (re)valorização da produção artesanal, este artigo tem como objetivo analisar os desafios enfrentados pelos agricultores familiares para se inserirem formalmente no mercado sul-catarinense. A região sul de Santa Catarina se caracteriza pela pequena propriedade rural, cuja base produtiva está voltada para o autoconsumo familiar, com a venda de excedentes em vários mercados, tais como feiras, programas institucionais, em domicílio e no comércio geral. Entretanto, esses produtores enfrentam barreiras para se inserirem formalmente no mercado, principalmente em função das legislações tributária e sanitária.

Quanto aos procedimentos metodológicos, foram realizadas pesquisas em acervos bibliográficos e documentais e entrevistas com oito membros de diretorias de seis cooperativas descentralizadas do sul catarinense. A escolha das cooperativas foi de forma intencional, por contemplarem os objetivos traçados neste artigo.

Em relação aos objetivos da análise, a pesquisa se caracteriza como exploratória e descritiva, por descrever as percepções dos entrevistados sobre os desafios da inserção nos mercados e como se estabelecem as relações entre o formal e o informal. Segundo Gil (2010), a maior parte dessas pesquisas envolve levantamento bibliográfico, entrevistas com pessoas que tiveram experiências práticas com o problema pesquisado e análise de exemplos que estimulem a compreensão.

A técnica de investigação adotada foi o estudo de caso, com pesquisa de campo, por meio da qual foram obtidos os dados primários coletados nas entrevistas, que foram realizadas com questionários semiestruturados, no decorrer do ano de 2016. Para a análise das informações coletadas, utilizou-se a técnica de análise de conteúdo, que, segundo Bardin (2015), permite uma leitura sistemática de primeiro plano do material empírico e, ao mesmo tempo, faculta uma interpretação rigorosa dos sentidos e significados dos depoimentos. 
O artigo está estruturado em cinco seções. Além desta parte introdutória e das considerações finais, a segunda seção apresenta a revisão bibliográfica referente ao objeto de estudo, e a terceira disserta sobre as cooperativas descentralizadas e as estratégias de formalização de produtos artesanais no mercado catarinense. A quarta seção trata dos desafios da inserção formal da produção artesanal no sul catarinense.

\section{OS desafios da inserção formal no mercado de produtos da agricultura familiar}

No Brasil, a agricultura familiar passou a ser reconhecida a partir da década de 1990, com a criação do Programa Nacional de Fortalecimento da Agricultura Familiar-PRONAF. Essa foi uma das primeiras políticas voltadas aos pequenos produtores, fazendo com que o foco das políticas públicas se voltasse para os agricultores familiares, que passaram a ser reconhecidos oficialmente como categoria. Conforme Abramovay (2007), são categorizados como agricultores familiares aqueles estabelecimentos cuja gestão e maior parte da força de trabalho são provenientes dos membros da família.

Mesmo com esse reconhecimento, os agricultores familiares ainda enfrentam grandes desafios para sair da informalidade, o que se torna uma ameaça à sua própria continuidade, uma vez que o mercado não tem espaço para a comercialização de produtos cujos processos de produção não se enquadram nos padrões de regulação vigentes (WILKINSON; MIOR, 1999).

O Brasil possui um imenso mercado agroalimentar artesanal, mesmo que uma parte expressiva seja informal. A existência da informalidade na produção e na comercialização de alimentos pode, em alguns casos, apresentar riscos à saúde dos consumidores, mas essa existência não diminui sua importância, pois é uma fonte relevante de produtos diferenciados cada vez mais apreciados pelos consumidores. Esse movimento é simbolizado pela crescente valorização das gastronomias regionais, na busca de "bons produtos" e, também, pelos crescentes questionamentos devido aos problemas socioambientais, causados pela produção em larga escala. Há, ainda, o movimento pelo "resgate do gosto", cujo representante mais expressivo é a rede formada pelo Slow Food, com o slogan: Os alimentos precisam ser "bons, limpos e justos" (DORIGON; RENK, 2014).

No meio acadêmico, mesmo nos organismos internacionais, conforme Wilkinson e Mior (1999), existem inúmeras definições para o “informal”, bem como avaliações positivas e negativas sobre o seu significado. Em um extremo, pode ser identificado como pobreza e/ou sonegação de tributos, enquanto no outro, como uma reação criativa à burocracia estatal e à inadequação na provisão de bens e serviços, tanto públicos como privados. Os autores diferenciam o setor informal do ilegal, pois os produtos ilegais são proibidos, como no caso da droga ou do contrabando. Já o informal, caracteriza-se por atividades cujos processos de produção não se enquadram nos padrões regulatórios vigentes. 
Dessa forma, o informal é definido, essencialmente, a partir das normas reguladoras do Estado, que sofrem alterações com o tempo. Quando há ausência de normas, não há base para a distinção entre o formal e o informal. A regulação do Estado se origina por motivações variadas, tais como: a) pressões sociais; b) interesses próprios ao Estado; c) ou, ainda, oportunidades e/ou ameaças provenientes de pressões internacionais (DORIGON, 2010). Ou seja, o informal é definido como uma atividade que não adota as normas ou parte delas que prevalecem em um determinado período.

Essa normatização, por um lado, no limite, pode representar a imposição de interesses específicos dentro do setor e a criação de barreiras à entrada. Por outro, pode expressar valores ou objetivos compartilhados, mas para os quais existem opções alternativas de normas e regulamentações que podem representar um ideal, refletir valores e conhecimentos consensuais, tanto do lado da produção quanto do consumo, cuja adoção implica custos proibitivos. Com essas ressalvas, existe certa convergência entre pequenos empreendimentos e a informalidade, especialmente em se tratando de produtores artesanais e pouco capitalizados (WILKINSON; MIOR, 1999).

Ressalta-se que as atividades informais são, na maioria das vezes, a única alternativa possível para os pequenos empreendimentos, ou seja, a única oportunidade de obtenção de renda e de manutenção da atividade. Segundo Hespanha (2009), em vez de existir a preferência pelo informal, o que se constata é a sua escolha racional. Para quem tem falta de recursos (não só monetários, mas também educacionais ou sociais), a solução formal pode ser inviável ou significar a sua extinção.

Nesse sentido, a incerteza quanto ao êxito do negócio torna proibitivo e muito arriscado o investimento na formalização da atividade (autorizações, licenças, impostos, etc.). Além disso, os sistemas fiscais e sanitários são excessivamente restritivos ou complexos para um empreendimento de pequena dimensão. Por ser o mercado um ambiente hostil e imprevisível, a informalidade representa uma estratégia para reduzir o risco de não o dominar totalmente.

Uma parte significativa da informalidade, contudo, segundo Wilkinson e Mior (1999), pode se constituir em esforços para burlar a legislação, ferindo o direito do trabalhador e/ou do consumidor. Para essa situação, não existe defesa. A informalidade também pode advir da burocracia excessiva, da difícil separação entre trabalho infantil e produção familiar, bem como da dificuldade para dominar as legislações sanitária e tributária (o desconhecimento pode representar o não cumprimento). 
Se os empreendimentos maiores optam pela informalidade, com pretextos de não cumprirem a legislação, a produção artesanal não deveria estar associada à informalidade. Todavia, a procura por produtos artesanais ${ }^{3}$ também envolve um contexto marcado pela perda de confiança na produção de alimentos padronizados em escala global (PLOEG, 2008).

Esse processo fez com que $\mathrm{O}$ alimento se desconectasse e se desenraizasse do local, gerando desconfiança quanto aos alimentos industrializados produzidos em larga escala. Isso possibilitou a expansão do mercado de produtos artesanais, cujo processo de produção é local, a partir de procedimentos socialmente sustentáveis e mais justos. Também houve mudanças no padrão de consumo e maior conexão entre o rural e o urbano.

Dessa forma, tem-se a possibilidade de maior integração entre produção e consumo, conforme Cruz e Schneider (2010), por meio de cadeias curtas em que há a valorização local dos produtos artesanais, com características histórico-culturais e enraizadas socialmente, ressaltando valores como confiança, localidade e reconhecimento entre produtores e consumidores e favorecendo dinâmicas socioeconômicas positivas.

Essa estratégia representa a possibilidade de desenvolvimento de algumas regiões, notadamente aquelas que têm procurado se inserir no mercado por meio da produção e da comercialização de alimentos que foram colocados à margem de redes hegemônicas de comercialização. A inserção se dá pela valorização dos produtos em espaços que os diferenciam daqueles altamente processados e produzidos em grande escala pelo sistema agroalimentar dominante, os quais são comercializados em mercados alternativos e institucionais.

Quando se refere ao sistema agroalimentar hegemônico, segundo Ploeg (2008), refere-se ao mercado controlado pelos impérios alimentares, onde há perda da identidade dos produtos. Dessa maneira, o alimento já não é mais produzido em um determinado lugar, por determinadas pessoas e em um determinado período e distribuído por meio de circuitos mais ou menos conhecidos. Pelo menos os consumidores conhecem a sua procedência.

$$
\begin{array}{r}
3 \text { Os produtos } \\
\text { artesanais recebem } \\
\text { inúmeras } \\
\text { denominações, tais } \\
\text { como: caseiros, da } \\
\text { roça, direto do } \\
\text { campo, coloniais, } \\
\text { entre outras. Para } \\
\text { efeitos do artigo, } \\
\text { utiliza-se o termo } \\
\text { “artesanal”, mas os } \\
\text { demais, quando } \\
\text { utilizados, são como } \\
\text { se fossem } \\
\text { sinônimos. }
\end{array}
$$


Esse processo é caracterizado, segundo o autor supracitado, pelo modo empresarial de fazer agricultura e por um grau elevado de modernização. A partir desse modelo, são criadas novas relações de dependência entre instituições, agentes e unidades agrícolas, as quais são de natureza dupla: incluem novas relações mercantis, bem como relações técnico-administrativas, por meio das quais o processo de trabalho é prescrito, condicionado e controlado.

Dessa forma, tem-se a crítica sobre a noção de qualidade presente no processo de produção industrial, cujas noções de eficiência e qualidade foram construídas ao longo do período Pós-Guerra, sob o seu domínio. A partir disso, segundo Wilkinson (1999), tenderam a predominar como justificativa da atividade econômica as noções de progresso técnico, a economia de escala, o trabalho qualificado e a adesão rigorosa aos padrões universais de produção.

Com isso, tem-se o debate sobre a qualidade dos alimentos: de um lado, o mercado formal institucionalizado pelos padrões de qualidade, certificado por meio de normas e regulamentos técnico-burocráticos; de outro, a dimensão da qualidade com base em valores culturais atribuídos ao mercado informal como mais confiável do ponto de vista dos consumidores. Além disso, novos desafios da produção agroalimentar se voltam para a segurança dos alimentos, para a busca de formas mais sustentáveis e socialmente justas (na observância das questões éticas e morais) de produção (CRUZ, SCHNEIDER, 2010).

Ainda em relação ao mercado informal e à diversidade de nomenclaturas que envolvem a classificação, neste artigo, entende-se como "informal" o mercado no qual os empreendimentos rurais não atendem exatamente a todas as exigências de normatização propostas pelos órgãos institucionais nas quais estão inseridos. Portanto, não seguem rigorosamente todos os requisitos institucionalizados pelo Estado, mas possuem o reconhecimento de grande parte dos consumidores, que qualificam os atributos artesanais como diferenciais frente aos produtos industrializados/ formalizados.

Os fatores culturais, segundo Dorigon (2010), são considerados mais importantes que os formais quanto à confiança e à preferência dos consumidores pelos produtos artesanais. Além disso, o mercado de produtos artesanais combina a produção para o autoconsumo, a venda entre parentes e vizinhos, as feiras e a colocação em diversos pontos de vendas.

A produção artesanal, conforme Oliveira e Mello (2006), transita entre o formal e o informal, que, de maneira geral, é comercializada em âmbito local e microrregional, seja em mercados populares, seja em novos mercados que surgem a partir de movimentos de valorização desses produtos, que abarcam uma grande diversidade e variedade.

Com o aumento da demanda por esses produtos, segundo Dorigon (2010), muitos produtores passam a ter condições de investir e de se adequar às exigências da formalização. Contudo, isso pode se tornar contraditório, porque à medida que o produtor atende às exigências formais, o produto pode se descaracterizar devido à mudança no processo produtivo do seu modo de saber-fazer, da sua essência cultural.

Sendo assim, muitos agricultores familiares são levados a enfrentar o seguinte dilema: para não serem excluídos, precisam investir em transformações 
nas suas estruturas produtivas, mas, ao fazê-lo, passam a perder mercado porque seus produtos deixaram de ser identificados como artesanais pelos consumidores.

O dilema da produção artesanal, conforme Wilkinson (2008), demonstra que esse tipo de produção está simultaneamente em um processo de adaptação aos padrões dominantes, como também em mobilização para impor um novo conjunto de padrões compatíveis com sua realidade socioeconômica.

Além disso, nas últimas décadas, ocorreram profundas transformações nas formas de intermediação entre a produção artesanal e o mercado, acesso que exige maior capacidade dos agricultores. O desafio, portanto, é elaborar tipologias de mercados que sejam relevantes para a agricultura familiar e construir uma base analítica que permita compreender a dinâmica desses mercados (WILKINSON, 2008).

Com base no autor supracitado, apresentam-se, resumidamente, no Quadro 1, três tendências ou dinâmicas de mercado para a agricultura familiar. A primeira, é a produção de commodities, como soja, milho, fumo, leite, suínos e aves, que são controladas pelas agroindústrias e atravessadores. A segunda, refere-se às iniciativas de agricultores e à construção de alternativas, contando com o apoio da extensão rural, de prefeituras e de universidades. A terceira dinâmica está relacionada às políticas públicas (de cunho não assistencialista) para o fortalecimento da agricultura familiar, com a criação de espaços específicos de comercialização.

Quadro 1. Espaços de comercialização da agricultura familiar

\begin{tabular}{|c|l|}
\hline Mercados & \multicolumn{1}{|c|}{ Características } \\
\hline Commodities & $\begin{array}{l}\text { Tem-se como exemplo a produção de tabaco, grãos, leite, suínos e aves, que } \\
\text { possui uma ligação com as grandes agroindústrias e os atravessadores. } \\
\text { Caracterizados pela padronização, legislação, qualidade mínima e escala. }\end{array}$ \\
\hline $\begin{array}{c}\text { Artesanais e/ou } \\
\text { Solidários }\end{array}$ & $\begin{array}{l}\text { Trata-se de uma forma diferenciada de produção e de comercialização, que conta } \\
\text { com a organização dos agricultores (cooperativas descentralizadas ou agricultura } \\
\text { familiar) e o apoio da extensão rural, de prefeituras e de universidades. São os } \\
\text { mercados de orgânicos e artesanais e as feiras. }\end{array}$ \\
\hline Institucional & $\begin{array}{l}\text { Toma-se como exemplo o PAA e PNAE do governo federal e governos estaduais. } \\
\text { São as compras realizadas pelo poder público na agricultura familiar. }\end{array}$ \\
\hline
\end{tabular}

Fonte: Adaptado de Wilkinson (2008).

Ainda com base no Quadro 1, ressalta-se que os agricultores familiares transitam em mais de um tipo de mercado, podendo ser dois ou até os três. Para amenizar suas dificuldades, a fim de que possam produzir e comercializar seus produtos formalmente no sul catarinense, surgiu a necessidade de se buscar alternativas para superar a informalidade.

A ideia inicial foi se organizarem em cooperativas que funcionariam nos moldes tradicionais, porém esse modelo não conseguia contemplar a grande variedade de produtos. O objetivo era organizar uma cooperativa que possibilitasse aos produtores formalizar a sua produção e comercializá-la sem a ameaça da informalidade e perda de direitos. Foi dessa maneira que surgiram as cooperativas descentralizadas em Santa Catarina. 


\section{As cooperativas descentralizadas e as estratégias da formalização de produtos artesanais em Santa Catarina}

Antes de abordar sobre as cooperativas descentralizadas, é necessário fazer uma distinção em relação às cooperativas tradicionais. Estas se encontram presentes nas mais diversas atividades econômicas, principalmente no setor agropecuário, e muitas delas estão vinculadas à exportação de commodities, à produção em larga escala e à uniformização dos produtos, com preços prédeterminados pelo mercado internacional. Nessas cooperativas, o agricultor continua sendo um produtor de matérias-primas.

As cooperativas descentralizadas, por sua vez, foram criadas para se adequarem à realidade das pequenas Unidades de Produção Familiar-UPFs do Estado de Santa Catarina. Se, por um lado, as UPFs apresentam aspectos positivos devido ao tamanho ao produzirem um produto diferenciado, por outro, tem-se o desafio quanto à sua formalização e viabilidade econômica. Com o intuito de manter as atividades de suas UPFs, muitos produtores buscaram se organizar em cooperativas descentralizadas, a fim de diminuírem custos com o processo de formalização, produção e comercialização.

A constituição das cooperativas descentralizadas no Estado de Santa Catarina, segundo Franz e Dalbello (2014), teve início no ano de 1998, quando um grupo de técnicos de instituições públicas e organizações não governamentais assumiram o desafio de elaborar uma proposta diferenciada para inserir no mercado formal os pequenos agricultores e seus empreendimentos. No sul catarinense, as primeiras cooperativas surgiram a partir de 2004.

O depoimento do dirigente de uma cooperativa descentralizada evidencia as diferenças entre as cooperativas:

\footnotetext{
[...] a cooperativa grande esquece que tem um associado, né? O objetivo da nossa cooperativa é o associado, é o trabalhador [...] nós, aqui, [...] temos este diferencial em relação às grandes, porque aqui a preocupação é com o associado, não é comprar patrimônio. [...] Nas grandes, o associado sempre ficou em segundo plano, [...], nós somos a favor das pequenas cooperativas, aquela que está mais próxima do agricultor, [...] a nossa foi criada pra isso [...] então, um dos desafios que a gente tem [...] é tentar orientar o agricultor a buscar alternativas [...], buscar o mercado [...], porque a cooperativa está aqui pra fazer os produtos passarem por aqui, pra sair com nota fiscal, pra eles venderem pros mercados por aí, em qualquer mercado, é isso que nós queremos, incentivar o agricultor a ficar na sua propriedade, [...]. As leis não é para o pequeno, é pro grande, então este é um problema sério para agricultura familiar (E7).
}

Nesse sentido, as cooperativas descentralizadas visam a, por meio da cooperação, amenizar os riscos da informalidade e acessar o mercado formalmente. Embora exista uma variedade de redes de cooperação em Santa Catarina, que compreendem outras formas de organização (condomínios, associações e cooperativas por produto), as cooperativas descentralizadas se constituem na mais recente forma de inovação organizativa da agricultura familiar (MIOR et al., 2014). 
No levantamento realizado pela Empresa de Pesquisa Agropecuária e Extensão Rural de Santa Catarina-Epagri em 2010, foram identificadas 70 cooperativas descentralizadas, com 4.755 sócios, integrando 401 empreendimentos como unidades descentralizadas. Nessa pesquisa realizada pela Epagri, foram identificadas 70 cooperativas de agricultura familiar por produto, 30 condomínios e 263 associações de agricultores familiares. No total, essas organizações agrupavam cerca de 21 mil agricultores familiares (MIOR et al., 2014).

Na pesquisa de campo realizada por Estevam, Lanzarini e Salvaro (2015), na mesorregião sul catarinense, foram detectadas 39 cooperativas descentralizadas, distribuídas nas três microrregiões, com aproximadamente 3.000 associados.

As cooperativas recebem essa denominação, descentralizadas, porque a produção é realizada nas UPFs que estão localizadas nas propriedades rurais, portanto, fora da sede da cooperativa (a sede geralmente é uma das UPFs, ou uma sala cedida pelo Sindicato dos Trabalhadores Rurais-STRs, ou um pequeno escritório alugado).

De acordo com Estevam, Lanzarini e Salvaro (2015), a formalização da UPF é feita por meio de um contrato de comodato de seção de uso entre o associado e a cooperativa. Conforme o Quadro 2, os produtos das UPFs são repassados à cooperativa por meio do bloco de nota do produtor. Esses produtos passam a ser da cooperativa. Depois, é emitida uma nota fiscal em nome da cooperativa. Dessa forma, o produto é comercializado com o rótulo da cooperativa e, para fins de formalização dos produtos, as UPFs passam a pertencer à cooperativa por intermédio do contrato de comodato.

Quadro 2. Fluxograma de formalização dos produtos e as UPFs na Cooperativa Descentralizada

\begin{tabular}{|c|c|c|}
\hline $\begin{array}{c}\text { Agricultor } \\
\text { (Entrada) }\end{array}$ & $\begin{array}{c}\text { Nota Fiscal da } \\
\text { Cooperativa } \\
\text { (Saída) }\end{array}$ \\
\hline
\end{tabular}

Fonte: Estevam, Lanzarini e Salvaro (2015).

Essas cooperativas têm possibilitado a formalização dos empreendimentos ante as legislações (tributárias, trabalhistas, sanitárias e ambientais) no Estado de Santa Catarina. De modo geral, as cooperativas descentralizadas são organizações que abrigam diversos empreendimentos e inúmeras atividades artesanais. São constituídas por uma sede administrativa e por UPFs descentralizadas que se situam nas propriedades dos associados.

Atualmente, essas cooperativas abrigam variadas UPFs descentralizadas, tais como: de produção de frutas, verduras, cereais, sucos, vinhos, licores, cachaça, doces, ovos, embutidos de carnes, massas, pizzas, pães, bolachas, biscoitos, entre outras. 
Normalmente, as UPFs são constituídas em um espaço que faz parte da residência dos cooperados. Quando é necessário serem construídas, os recursos são dos próprios cooperados e/ou com apoio de políticas públicas. Embora as UPFs sejam repassadas pelo contrato de comodato à cooperativa, a responsabilidade pelo patrimônio é do cooperado. Nesse modelo de cooperativa, quando houver a desistência de um cooperado ou de um grupo de sócios, esse fato não causará maiores impactos à cooperativa nem para o conjunto de associados, porque todo investimento é feito pelo associado. Nesse caso, a cooperativa deve buscar outros cooperados para suprir possíveis problemas de produção ou de número de sócios que, pela legislação, são no mínimo 20 sócios para se constituir uma cooperativa (LANZARINI, 2017).

Como a produção é descentralizada, o associado tem certa flexibilidade sobre o que, quanto e como irá produzir. Isso também é decidido e planejado em assembleia. Nesse modelo de cooperativa, não existe vínculo empregatício entre a cooperativa e seus cooperados. A prestação de serviços dos associados nas UPFs não gera passivos trabalhistas à cooperativa, desde que todos os membros da família sejam sócios. Quando/se uma UPF contratar funcionários, o contrato deverá ser efetuado por intermédio da cooperativa e não pelo associado, pessoa física. Nessas condições, o cooperado não perde a condição de segurado especial no Instituto Nacional do Seguro Social-INSS para fins de aposentadoria e outros benefícios, como a comercialização para os mercados institucionais (LANZARINI, 2017).

Em relação à comercialização da produção, na maioria das cooperativas, são os próprios cooperados que realizam a venda e a entrega dos produtos diretamente aos consumidores, quer seja nas feiras, quer seja em casa. Além disso, a venda é feita em pequenos comércios (mercados, mercearias e padarias), em redes de supermercado e no mercado institucional (nesse caso, é intermediada pela cooperativa). A diversificação dos dispositivos mercantis é uma estratégia recorrente utilizada pelos cooperados, tanto para produtos in natura como para aqueles minimamente processados nas UPFs.

A primeira cooperativa descentralizada do sul catarinense foi a Cooperativa Agroindustrial Familiar de Nova Veneza-Coofanove, criada em 2004. O objetivo de sua fundação foi a formalização da produção de produtos da agricultura familiar do Município de Nova Veneza (SC). O processo de criação da Coofanove remonta ao fim da década de 1990, quando, semanalmente, um grupo de agricultores se reunia para comercializar produtos em uma feira que funcionava junto à rodoviária municipal. Essa feira teve suas atividades encerradas devido à recorrente apreensão de produtos por parte da fiscalização. Consequentemente, foi interditada, não sendo mais possível comercializar no local. Dessa forma, os feirantes foram incentivados pelos órgãos de extensão a criarem a cooperativa. Foi assim que surgiu a primeira cooperativa descentralizada da região e depois as demais. 


\section{Os desafios da inserção formal da produção artesanal no sul catarinense}

A mesorregião do sul catarinense é composta por três microrregiões: Tubarão, Criciúma e Araranguá. Conforme os dados do Instituto Brasileiro de Geografia e Estatística-IBGE (2015), tem área territorial de 9,71 mil km² e representa 10,1\% dos 95,7 mil km² de área territorial de Santa Catarina. Consoante essa mesma fonte, a população residente na região era de 925,1 mil pessoas, representando 14,8\% da população estadual (IBGE, 2015).

Nessa mesorregião, segundo a mesma fonte de informação acima, a participação da agricultura familiar é relevante, sobretudo em termos socioeconômicos, pois 38\% da população residem em áreas rurais. Contudo, os agricultores enfrentam dificuldades de acesso ao mercado devido às exigências da legislação (fiscal, trabalhista e sanitária). Por isso, em certa medida, a persistência do caráter informal envolvido na comercialização de muitos produtos. Em tal contexto, as cooperativas descentralizadas se apresentam como forma de superar as barreiras da informalidade, bem como de oportunizar a participação autônoma dos agricultores nos mercados.

Na região, assim como no Estado e País, a produção e a comercialização da agricultura familiar transitam entre o formal e o informal (ESTEVAM; SALVARO, 2016), conforme apresentado no item anterior. Essa separação é de difícil distinção, pois a produção é realizada, primeiramente, para o autoconsumo e, posteriormente, a parte excedente é trocada entre parentes e vizinhos e também comercializada no mercado. Esses produtos são comercializados, sobretudo, em feiras-livres, em vendas diretas na própria UPF, em programas institucionais e em pequenos mercados (ESTEVAM; SALVARO, BUSARELO, 2015).

Conforme já referido, as cooperativas descentralizadas foram criadas para enfrentar os problemas da informalidade depois da apreensão de produtos, pagamentos de multas, processos na justiça, entre outros entraves. Nesse sentido, elas representam uma "proteção" jurídica à informalidade ao oportunizarem a participação formal nos mercados. Entretanto, existem dificuldades na distinção entre o formal e o informal. No depoimento abaixo, fica caracterizada a dualidade na participação dos mercados:

a venda pro PNAE e PAA representa $50 \%$ da renda, a gente ainda vende pro [...] né? Ainda em outros lugares, né? A gente tem a feirinha assim, [...] a gente faz de porta em porta, é um dia por semana, a gente sai pra entregar, [...] já temos os clientes, tudo certo, é só chegar e entregar. A feira a gente participa, [...]. Esse outro $50 \%$ tu consegue com essa venda de casa em casa, principalmente (E1).

Com base na afirmação acima, percebe-se que a comercialização da produção é realizada uma parte formalmente e a outra não (de porta em porta). Como ressalta Dorigon (2010), os produtos artesanais são inseridos no mercado pelas relações de confiança estabelecidas entre produtores e consumidores, geralmente familiares, vizinhos ou pessoas da comunidade, mesmo com os obstáculos dos marcos regulatórios, que restringem esse tipo de comércio. Verificase, no entanto, que essa relação de proximidade se mantém viva, mesmo com a possibilidade da formalização por meio da cooperativa. 
O entrevistado 8, além da produção "pro gasto", também participa de feiras e dos programas institucionais, mas, como já foi destacado, primeiro é a produção para o consumo da família, somente o excedente é comercializado. Além disso, também há a produção de produtos feitos exclusivamente para o mercado, como é o caso dos panificados:

pro gasto, a gente produz o milho e o feijão, que dá até pra vender, a gente traz pra feira [...]. Na unidade familiar nóis fizemos assim: bolachas, pão, bolo, a gente faz para merenda escolar, daí o feijão que sobra a gente comercializa, o aipim que sobra a gente vende, [...]. Na nossa unidade, a gente também faz a broa de polvilho azedo, a rosquinha de milho, bolacha de nata, pão integral [...]. Ah, tem a paçoca [...], a gente vende pra feira, vende em casa e, também, nos mercadinho (E8).

Com base nas exposições dos entrevistados, constata-se a importância dos programas institucionais na composição da renda familiar dos cooperados, bem como a importância das feiras:

Nós temos um cliente que é [...] o hospital X, entregamos os produtos, né? Frutas e verduras, [...] a gente fornece, né? $\mathrm{E}$ faz uns quatro ou cinco anos que a gente tá caindo mais no ramo institucional, mas nosso "carro chefe" hoje é a feira livre, né? (E2).

A venda para o hospital tem grande representatividade na composição da renda, mas o destaque é a feira-livre. A venda direta, segundo Schneider e Ferrari (2015), seja em feiras ou em domicílios, é um mecanismo comumente utilizado pelos produtores artesanais, caracterizando-se em um importante canal de acesso da agricultura familiar.

São vendas que se repetem em contatos diretos e que confirmam a reputação de um produto e sua qualidade a partir da confiança gerada nessa relação. Por meio desse tipo de comércio direto, o produtor obtém maior ganho pelo seu produto, já que dispensa a participação de intermediários no negócio.

Para o entrevistado 3, a principal renda é obtida com a produção e a comercialização de banana, que é vendida, em parte, para os programas institucionais e no comércio em geral. A renda é complementada com a produção de hortigranjeiros para o autoconsumo e para o mercado local.

[...] a parte aí do horti, né, toda a parte de verdes, vamos dizer, assim, é produzida aqui pro consumo da família e participo do comércio local aqui, que são algumas fruteiras na região e governo. A outra parte da venda eu faço pro Rio Grande do Sul, que foi a questão pioneira nossa da banana desde a geração dos meus avós, e mantidos até hoje (E3).

Como se observa, a tradição familiar na produção de bananas já está na terceira geração. Para Schneider e Ferrari (2015), esses mercados acabam sendo o prolongamento de relações familiares, de amizade e de pertencimento, construídos ao longo do tempo. Ainda, para Dorigon (2010), o mercado é menos importante, enquanto lugar de transações monetárias, que a reciprocidade obtida como meio para a reprodução familiar. Com isso, tem-se o ambiente necessário para a reprodução do patrimônio familiar de um modo de saber-fazer. $O$ depoimento do entrevistado 3 corrobora a afirmação do autor de que no meio rural, muitas vezes, 
os fatores econômicos são menos importantes que outros aspectos, como a qualidade de vida, por exemplo.

Tenho o nível superior completo, pós-graduação em Gestão Empresarial. Eu era [...] supervisor comercial. Eu tinha um bom salário. Eu conheci o Brasil todo. Eu dormia bem. Eu comia bem. A minha estrutura de vida era uma estrutura de um padrão médio pra alto. Só que como eu rodava de 6 a 8 mil quilômetros por mês, longe de casa, [...], eu optei em retornar pra agricultura pela questão da qualidade de vida (E3).

Em relação aos programas institucionais, não se questiona sua significância na composição da renda dos cooperados. Contudo, os entrevistados apontaram algumas dificuldades relativas à sua execução, não em relação à informalidade, mas ao atraso na liberação dos recursos, ao baixo valor pago aos produtos, aos custos não cobertos na entrega dos produtos, entre outras. Os depoimentos abaixo acrescentam outros entraves dos Programas:

Eu vendo pro... pro PNAE, né? PNAE é [...] Mas eu não sei, eu tô pensando seriamente parar de vender, por causa do prazo: o Governo demora muito pra pagar, não tem como trabalhar com eles. [...] além do grande entrave [...] que é a legislação. Isso que trava muito, na área das licenças, na área de processar o produto, muita legislação, muita burocracia, [...] então é difícil de trabalhar por causa disso (E6).

É assim ó: o que eu vejo nesses programas, seriam uns programas muito bons, só porque na realidade não funciona como teria que funcionar [...]. Porque existe muita politicagem dentro disso tudo, através de quem tá dirigindo os municípios, por exemplo, daí sobra pra quem tá querendo vender o produto. Mesmo sendo legalizado, às vezes não consegue [...] Nós, por exemplo, a gente conseguiu vender um ano pra prefeitura $X$, no segundo ano a gente já foi barrado e não conseguiu mais vender. Então já tem [...] um ciclo vicioso ali de supermercados, de quem tá ali por dentro, que já quer vender lá 'bolacha Maria', por exemplo. Agora se tu quer vender a bolacha, não sei de tal [...] não consegue [...]. Lá tem comum acordo com quem compra e quem vende, funciona dessa forma, então é uma coisa assim que deveria ter uma fiscalização [...] pra que isso funcionasse realmente direito, porque a lei do governo federal diz que $30 \%$ seria pra vender pra merenda escolar da agricultura familiar (E4).

Esses entraves apontados pelos entrevistados na execução do PNAE, para Assis Júnior et al. (2014), são resultados da ausência de diálogos entre os atores envolvidos (gestores públicos municipais, agricultores e assistência técnica), fato que traz muitos prejuízos à sua execução e reflete, por vezes, nos resultados insatisfatórios dessa política pública. Por isso, o desafio para o mercado institucional seria o poder público viabilizar meios para que os agricultores familiares possam efetivamente comercializar seus produtos com menos obstáculos.

De modo geral, a cada mudança na legislação e devido às inovações tecnológicas, novos desafios são postos e precisam ser superados pela agricultura familiar. Com isso, o Estado aumenta o seu poder de controle e interferência sobre a produção artesanal, novos desafios surgem permanentemente para a produção artesanal. 
Então [...] tem que saber [...] desde a nota fiscal que é tirada eletrônica, [...], isso é feito, e dá muito trabalho, e é uma das partes mais difíceis, porque o plantar não é trabalhoso, [...], o mais trabalhoso, hoje, é a parte burocrática, são os papéis, e são muitos! As exigências são muito grandes, muito grandes! Por isso que tem muitos que desistem no meio do caminho. [...] tem muita exigência, né? O próprio Ministério da Agricultura [...], o próprio Estado, a própria prefeitura, então é algo muito exigido [...] é tudo muito rastreado [...] (E5).

As exigências na legislação geram muitos desafios à produção artesanal. Segundo Dorigon (2010), vem crescendo desde a década de 1970, quando foram instituídas as primeiras normas técnicas e sanitárias que acompanharam a implantação e a difusão dos complexos agroindustriais no Brasil. Por ter escalas de produção e processos fora dos parâmetros da agroindústria, a produção artesanal foi deslocada para o setor informal, situação que se repete a cada mudança na legislação, pois novos padrões são impostos, fazendo com que mais produtos artesanais sejam deslocados para a informalidade.

Como constatado pela pesquisa de campo, os desafios para formalizar as UPFs, embora sejam imensos, os produtos artesanais estão em expansão na região. Na realidade, a comercialização de parte da produção na informalidade não está somente relacionada à precariedade de recursos dos agricultores, mas, em parte, devido às dificuldades na emissão da nota fiscal eletrônica e, às vezes, devido à pequena quantidade comercializada ou às dificuldades em dominar a tecnologia na emissão da nota ou em locais sem internet.

Nesse sentido, os desafios a serem superados pelos agricultores familiares e suas cooperativas descentralizadas no sul catarinense, neste momento para mitigar os problemas com a informalidade, são os seguintes: facilitar a emissão da nota fiscal eletrônica, implantar o sistema de rastreabilidade dos produtos, mudanças na legislação sanitária e fiscal, entre outros.

\section{Considerações Finais}

No sul catarinense, assim como no Estado de Santa Catarina, as iniciativas realizadas para formalizar os produtos artesanais contam com o apoio da Epagri, de prefeituras municipais, de universidades, de STRs, dentre outras instituições. Essas iniciativas resultaram na criação de inúmeras organizações coletivas, como são as experiências das cooperativas descentralizadas. Dessa maneira, para os cooperados, as cooperativas têm sido uma alternativa para a comercialização da produção, sem os riscos da informalidade.

Os desafios da informalidade, todavia, são constantemente renovados a cada mudança na legislação. A alteração pode ocorrer em uma norma ou em um regulamento, criando novos obstáculos, como foi o caso da obrigatoriedade da emissão da nota fiscal eletrônica, pois muitas propriedades não têm internet, ou a tecnologia não é compatível para a emissão, ou, às vezes, a quantidade comercializada é pequena, ou, ainda, os aspectos culturais (no caso da venda entre parentes ou vizinhos, esta, muitas vezes, não é encarada como negócio). O outro desafio é a rastreabilidade dos produtos, que exige novas adaptações na produção e comercialização. 
Cabe ressaltar que a produção artesanal surgiu muito antes dos marcos regulatórios e faz parte da tradição cultural do mundo rural. Ela se amplia pela força da demanda por produtos diferenciados. Contudo, a regulação dos mercados pode ser considerada um terreno privilegiado de definição de interesses distintos. 0 estabelecimento de normas não se faz apenas baseado em critérios neutros de eficiência ou de interesse público, pois é um processo de negociação sobre o que deve ou não constar no momento de estipular as regras e normas. Nesse sentido, o informal também representa a outra face da natureza excludente da sociedade brasileira.

O movimento de organizações coletivas de agricultores na região por autonomia e construção de alternativas não é apenas uma ação de resistência para superar as barreiras da informalidade. Na realidade, trata-se de uma estratégia criativa para manter e ampliar o mercado, bem como valorizar e recuperar processos artesanais de um "saber-fazer" vinculado ao patrimônio histórico e cultural que estava em processo de desaparecimento. Na prática, criam-se novas formas de inserção em mercados, como acontece com a organização de cooperativas descentralizadas, cujos agricultores são protagonistas e contam com a parceria de diversos atores estratégicos.

Os mercados são o prolongamento de relações pessoais de parentesco, amizades e vizinhanças construídas ao longo do tempo. Esses laços estreitos atestam a notoriedade dos produtos e sua qualidade a partir da confiança gerada nessas relações de proximidade. Nesse sentido, as formas predominantes de acesso aos mercados, sobretudo na região, são concretizadas nas vendas diretas (nas UPFs, nas feiras, em pequenos mercados e em domicílios), e, em parte, as transações ocorrem informalmente. Isso é um indicativo de como os mercados para os produtos dos cooperados são socialmente construídos. As relações de confiança estabelecidas entre produtores e consumidores alicerçam as trocas e os pequenos negócios envolvidos na produção artesanal. As redes formadas, alinhadas com base em valores culturais, são os contrapontos ao padrão agroindustrial dominante.

\section{REFERÊNCIAS}

ABRAMOVAY, R. Paradigmas do capitalismo agrário em questão. São Paulo: EdUSP, 2007.

ASSIS JÚNIOR, I. A. et al. Promoção do desenvolvimento rural via políticas sociais: O caso da inserção da agricultura familiar no Programa Nacional de Alimentação Escolar no Rio Grande do Norte de 2011-2012. Tekhne e Logos, Botucatu, SP, v. 5, n. 2, p. 15-33, 2014. Disponível em: <http://fatecbt.edu.br/seer/index.php/tl/article/view/310> Acesso em: 02 ago. 2017.

BARDIN, L. Análise de Conteúdo. Lisboa, Portugal: Edições 70, 2015.

CRUZ, F.; SCHNEIDER, S. Qualidade dos alimentos, escalas de produção e valorização de produtos tradicionais. Rev. Bras. de Agroecologia, v. 5, n. 2, p. 22-38, 2010. Disponível em: <http://orgprints.org/24508/1/Cruz_Qualidade.pdf>. Acesso em: 13 jun. 2017. 
DORIGON, C. O Mercado Informal dos Produtos Coloniais da Região Oeste de Santa Catarina. In: Encontro Nacional de Estudos do Consumo - ENEC, 5. Rio de Janeiro, 2010. Anais eletrônicos... Rio de Janeiro: Grupo de Estudos do Consumo e da Associação Nacional de Estudos do Consumo, 2010. Disponível em: <http://www.estudosdoconsumo.com.br/artigosdoenec/5.2.3-Dorigon-

O_mercado_informal_dos_produtos_coloniais.pdf>. Acesso em: 29 jul. 2017.

- RENK, A. O Mercado Informal dos Produtos Coloniais como Mercado Contestado. In: Encontro Nacional de Estudos do Consumo - ENEC, 7., Rio de Janeiro, 2014. Anais eletrônicos... Rio de Janeiro: Grupo de Estudos do Consumo e da Associação Nacional de Estudos do Consumo, 2014. Disponível em: <http://www.estudosdoconsumo.com.br/artigosdoenec/ENEC2014-GTo8-

O_mercado_informal_dos_produtos_coloniais_como_mercado_contestado.pdf $>$. Acesso em: 19 jul. 2017.

ESTEVAM, D. O.; SALVARO, G. I. J. A fronteira entre o mercado (in)formal de produtos da agricultura familiar no sul de Santa Catarina, Brasil. In: XI Iberian Conference on Rural Studies (XI CIER), Vila Real - Portugal. Book of proceedings of the 11th Iberian Conference on Rural Studies. Vila Real: UTAD, v. XI. p. 110-115, 2016. Disponível

em: <http://xicier2016.utad.pt/sites/all/themes/professional_responsive_theme/images/fi les/Book_proceedings.pdf>. Acesso em: 04 ago. 2017.

- BUSARELLO, C. S. Espaços de produção e comercialização da agricultura familiar: as cooperativas descentralizadas do Sul Catarinense. Interações, Campo Grande, v. 16, ํo 2, p. 289-299, jul./dez. 2015. Disponível em: <DOI: http://dx.doi.org/10.1590/151870122015205>. Acesso em: 19 jul. 2017.

. LAZARINI, J. J. S.; SALVARO, G. I. J. O custo operacional das cooperativas descentralizadas da região sul de Santa Catarina. Revista de Contabilidade da UERJ, Rio de Janeiro, v. 19, n. 3, p. 36-46, jan./abr. 2015. Disponível em: <http://www.epublicacoes.uerj.br/index.php/rcmccuerj/article/view/12377/pdf >. Acesso em: 26 jul. 2017.

FRANZ, D.; DALBELLO, O. A trajetória de construção das cooperativas descentralizadas no Alto Uruguai Catarinense. In.: ESTEVAM, D. O.; MIOR, L. C. (Orgs.). Inovações na agricultura familiar: as cooperativas descentralizadas em Santa Catarina. Florianópolis: Insular, 2014, p. 55-69.

GIL, A. C. Como elaborar projetos de pesquisa. 5. ed. São Paulo: Atlas, 2010.

HESPANHA, P. Microempreendedorismo. In.: CATTANI, A.; LAVILLE, J-L.; GAIGER. L. I.; HESPANHA, P. Dicionário Internacional da Outra Economia. Coimbra: Edições Almedina S.A., 2009, p. 248-254. Disponível em: <http://www.jornaldomauss.org/periodico/wp-content/uploads/2009/06/dicionariointernacional-da-outra-economia.pdf $>$. Acesso em: 17 jul. 2017. 
IBGE - Instituto Brasileiro de Geografia e Estatística. Síntese de indicadores sociais: uma análise das condições de vida da população brasileira. Rio de Janeiro: IBGE, 2015, p. 1-137.

LANZARINI, J. J. S. Cooperativas Descentralizadas de agricultores familiares: aspectos do Contrato de Comodato. Criciúma/SC: Dissertação apresentada ao Programa de Pós-Graduação em Desenvolvimento Socioeconômico da Universidade do Extremo Sul Catarinense - PPGDS/UNESC, 2017. 169 p.

MIOR, L. C. et al. Inovações organizacionais da agricultura familiar no Sul Catarinense. In: ESTEVAM, D. O.; MIOR, L. C. (Orgs.). Inovações na agricultura familiar: cooperativas descentralizadas em Santa Catarina. Florianópolis, SC: Insular, 2014, p. 21-53.

. Redes, agroindústrias familiares e os novos mercados em Santa Catarina. In: ESTEVAM, D. O.; MIOR, L. C. (Orgs.). Inovações na agricultura familiar: as cooperativas descentralizadas em Santa Catarina. Florianópolis: Insular, 2014, p. 73100.

OLIVEIRA, D.; MELLO, M. A. Novas formas de inserção da agricultura familiar ao mercado como estratégia de desenvolvimento rural. In: CONGRESSO DA SOBER, 44. Fortaleza, 2006. Anais... Fortaleza: Sober, p. 1-19. Disponível em: <http://www.sober.org.br/palestra/5/808.pdf>. Acesso em: 24 jul. 2017.

PLOEG, J. D. Camponeses e Impérios Alimentares: lutas por autonomia e sustentabilidade na Era da Globalização. Porto Alegre: UFRGS Editora, 2008.

SCHNEIDER, S.; FERRARI, D. L. Cadeias Curtas, cooperação e produtos de qualidade na Agricultura Familiar: o processo de relocalização da produção agroalimentar em Santa Catarina. Organizações Rurais \& Agroindustriais, Lavras, v. 17, n. 1, p. 56-71, 2015. Disponível em: <http://revista.dae.ufla.br/index.php/ora/article/view/949/475>. Acesso em: 01 ago. 2017.

WILKINSON, J. Mercados, redes e valores: o novo mundo da agricultura familiar. Porto Alegre: Editora da UFRGS, 2008.

- A contribuição da teoria francesa das convenções para os estudos agroalimentares: algumas considerações iniciais. Ensaios FEE, Porto Alegre, v. 20, n. 2, p. 64-80, 1999. Disponível em: <file:///C:/Users/Casa/Downloads/1951-8052-1PB\%20(1).pdf>. Acesso em: 03 ago. 2017.

- MIOR, L. C. Setor informal, produção familiar e pequena agroindústria. Estudos Sociedade e Agricultura, no 13, p. 29-45, 1999. Disponível em: <http://r1.ufrrj.br/esa/V2/ojs/index.php/esa/article/viewFile/159/155>. Acesso em: 26 jul. 2017. 
Os desafios da inserção formal de produtos da agricultura familiar no mercado

DIMAS DE OLIVEIRA ESTEVAM. Professor do Curso de graduação em Economia e do Mestrado em Desenvolvimento Socioeconômico da Universidade do Extremo Sul Catarinense-Unesc.doe@unesc.net

GIOVANA ILKA JACINTO SALVARO. Professora do Curso de Mestrado em Desenvolvimento Socioeconômico (PPGDS) da Unesc. giovanailka@gmail.com

VANDA JANDIRA DALA DOS SANTOS. Graduanda do Curso de Ciências Econômica da Universidade do Extremo Sul Catarinense - UNESC. vanda@unesc.net 